\title{
Pengembangan Soal Ujian Sekolah Matematika Tipe Hots Tingkat SD
}

\author{
Leny Dhianti Haeruman ${ }^{1}$, Devi Eka W. $\mathbf{M}^{2}$ \\ Program Studi Pendidikan Matematika, Universitas Negeri Jakarta \\ Email: ${ }^{1}$ lenydhianti@unj.ac.id; ${ }^{2}$ deviekawm@unj.ac.id
}

\begin{abstract}
Mathematics learning in the current era is not sufficient by giving ordinary math problems that have been frequently given but it must focus a lot on solving problems that require high-level thinking skills so that today's teachers are expected to be able to develop Higher Order Thinking Skills (HOTS) type questions, namely questions -a problem that can be solved by someone who has the ability to think (cognitive) level. This study aims to: (1) Produce HOTS questions for elementary school level, (2) See the potential effect of HOTS questions on student learning outcomes. This study uses development research which consists of analyzing, designing, evaluating, and revising. This study used a HOTS-type written test consisting of 9 multiple choice questions and 2 description questions. All data collected were then analyzed descriptively qualitatively. The subjects in this study were 25 grade 6 students of SDN Jati Asih. The results of the data analysis concluded that (1) This study has produced a product of HOTS type school exam questions that are valid and practical. (2) the prototype of HOTS type questions developed has a positive potential effect on student test results, this can be seen from the results of students' answers which show that students are able to analyze, identify and create questions well and $88 \%$ of students are able to get excellent grades.
\end{abstract}

\section{Keywords: Development, School Exam Questions, Mathematics, HOTS}

\begin{abstract}
Abstrak. Pembelajaran matematika pada era saat ini tidak cukup dengan pemberian soal matematika biasa yang sudah sering kali diberikan namun harus banyak menitikberatkan pada pemecahan masalah yang membutuhkan kemampuan berpikir tingkat tinggi sehingga guru saat ini diharapkan mampu mengembangkan soal bertipe Higher Order Thinking Skills (HOTS), yaitu soal-soal yang mampu dipecahkan oleh seseorang yang mempunyai kemampuan berpikir (kognitif) tingkat. Penelitian ini bertujuan untuk : (1) Menghasilkan soal-soal HOTS tingkat Sekolah Dasar, (2) Melihat potensial efek soal-soal HOTS terhadap hasil belajar siswa. Penelitian ini adalah penelitian pengembangan yang dilakukan dengan Langkah analisis, membuat desain, melakukan evaluasi, dan merevisi. Penelitian ini menggunakan tes tertulis bertipe HOTS yang terdiri atas 9 soal pilihan ganda dan 2 soal uraian. Semua data yang dikumpulkan selanjutnya dianalisis secara deskriptif kualitatif. Subjek dalam penelitian ini adalah 25 siswa kelas 6 SDN Jati Asih. Hasil analisis data menyimpulkan bahwa (1) Penelitian ini telah menghasilkan suatu produk soal ujian sekolah tipe HOTS yang valid dan praktis. (2) prototype soal tipe HOTS yang dikembangkan memiliki efek potensial yang positif terhadap hasil tes siswa, hal ini terlihat dengan hasil jawaban siswa yang menunjukkan bahwa siswa sudah mampu menganalisis, mengidentifikasi dan mengkreasi soal dengan baik serta $88 \%$ siswa mampu mendapatkan niai sangat baik.
\end{abstract}

\section{Kata Kunci: Pengembangan, Soal Ujian Sekolah, Matematika, HOTS}

\section{PENDAHULUAN}

Saat ini matematika merupakan kebutuhan universal yang mendasari perkembangan teknologi modern saat ini dan mempunyai peran penting dalam berbagai disiplin ilmu dan juga dalam mengembangkan daya pikir manusia. Oleh karena itu, setiap orang diharapkan dapat menjadi melek matematika atau sering disebut dengan mathematical literacy sehingga mampu menghadapi tantangan di masa depan dalam persaingan global untuk proses pengambilan keputusan atau decision making dalam pemecahan masalah sehari-hari karena manusia dituntut untuk mempunyai pola pikir maju dari waktu ke waktu.

Pembelajaran matematika pada era saat ini tidak cukup dengan pemberian soal matematika biasa yang sudah sering kali diberikan, karena kita akan tidak dapat bersaing dengan orangorang yang sudah mengerjakan soal-soal matematika dengan tipe, model dan tingkat kesulitan yang berbeda.

Salah satu studi internasional yang mengukur kemampuan siswa di bidang 
Matematika dan Sains adalah TIMSS. TIMSS diawali pada tahun 1995. Pada tahun 2015 target populasi siswa Indonesia pada TIMSS adalah siswa kelas 4 SD dan bertujuan untuk mengukur capaian Matematika dan Sains siswa SD/MI pada studi internasional (Litbang Kemdikbud, 2015. Dibandingkan dengan beberapa negara di Asia, Indonesia saat ini berada di posisi bawah dan itu merupakan tantangan para akademisi khususnya guru di Indonesia. Hasil tersebut cukup memprihatinkan bagi sistem pendidikan di Indonesia. Hasil tersebut menjadi alasan logis bahwa guru saat ini diharapkan mampu mengembangkan soal bertipe Higher Order Thinking Skills (HOTS), yaitu soal-soal yang mampu dipecahkan oleh seseorang yang mempunyai kemampuan berpikir (kognitif) tingkat tinggi atau bertipe setidaknya $\mathrm{C} 4$ bahkan C6 jika merujuk pada taksnomi Bloom. Selain membagi tingkat kesulitan menggunakan taksonomi Bloom, guru juga dapat membagi pertanyaan soal bertipe HOTS kedalam tiga level, yaitu Level 1 (L1), level 2 (L2) dan level tiga (L3). L1 memuat level kognitif C1 dan C2, L2 memuat level kognitif C3 dan C4 sedangkan L3 memuat level kognitif C5 dan C6. Namun masih banyak guru yang belum memahami dan menguasai dalam mengembangkan soal HOTS. Hindari membuat pertanyaan yang sering ditanyakan baik pada buku paket ataupun soalsoal di internet. Pada era saat ini sudah saatnya guru mengupdate pengetahuan dan kemampuan mengajar serta memilah materi pelajaran dan soal-soal dengan mencari referensi lain yang dapat menunjang kualitas soal. Guru harus sering melatih siswa dalam menjawab pertanyaanpertanyaan bertipe HOTS.

Pada penyusunan soal-soal bertipe HOTS, soal tidak harus dibuat sesulit mungkin, sehingga membuat bingung dan membuang banyak waktu membacanya akan tetapi soal bertipe HOTS tersebut disusun secara sistematis, efektif dan proporsional untuk mengukur Indikator pencapaian Kompetensi (IPK) serta memiliki kedalaman materi yang kaya akan konsep sehingga siswa pun terangsang untuk menjawab pertanyaan dengan baik. Pada pemberian soal kemampuan berpikir tingkat tinggi (HOTS), guru tidak hanya menguji ingatan siswa, melainkan menguji pemahaman siswa yang mendalam sehingga siswa dituntut untuk dapat memberikan gagasan kreatif terhadap informasi-informasi yang diberikan pada soal tersebut jadi siswa dapat bernalar (reasoning) bukan hanya sekedar mengingat informasi.

Taksonomi Bloom dianggap merupakan dasar bagi proses berpikir tingkat tinggi. Pemikiran ini didasarkan bahwa beberapa jenis pembelajaran memiliki manfaat- manfaat lebih umum dan proses kognisi yang lebih daripada yang lain. Dalam mengembangkan soal-soal tipe HOTS, yang harus diperhatikan adalah apa saja indikatior-indikator pada soal HOTS tersebut. Krathwohl (2002) dalam bukunya yang berjudul "A revision of Bloom's Taxonomy: an overview Theory Into Practice" (1). Analisis. Informasi yang masuk harus dianalisis terlebih dahulu dan pisahkan berdasarkan factor penyebab yang kompleks hingga sederhana (2). Evaluasi yaitu menilai solusi atau ide berdasarkan kriteria tertentu yang telah ditetapkan lalu membuat dugaan sementara dan menguji hipotesis tersebut hingga membuat keputusan akhir berupa penerimaan atau penolakan(3). Kreasi, yaitu menggeneralisasi ide lalu mendesain cara dalam mencari solusinya hingga ditemukannya suatu struktur baru.

Penelitian ini bermaksud untuk mengisi kesenjangan yang ada dalam penelitian yang telah dilakukan atau literatur. Oleh karena itu, penelitian ini akan mengembangkan soal-soal ujian sekolah tipe HOTS tingkat Sekolah Dasar. Sehubungan dengan hal tersebut, Adapun tujuan penelitian adalah sebagai berikut::

1. Menghasilkan soal-soal HOTS tingkat Sekolah Dasar.

2. Melihat potensial efek soal-soal HOTS terhadap hasil belajar siswa

\section{METODE}

Subjek penelitian ini adalah siswa kelas 6 SDN Jati Kramat VIII dengan tingkat kecerdasan bervariasi. Metode penelitian ini adalah pengembangan dengan alur seperti pada gambar berikut ini. 


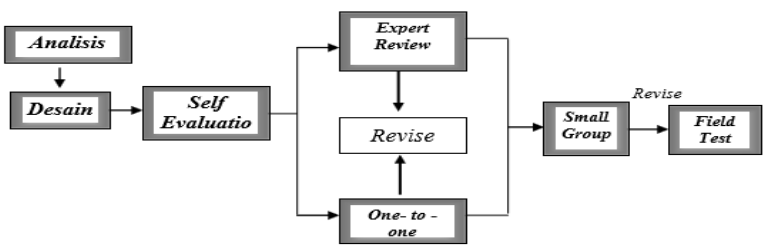

Gambar 1. Alur Desain Formative Evaluation (Tessmer, 1993)

Terdapat tiga tahap pada penelitian pengembangan dalam menghasilkan soal-soal untuk mengukur kemampuan berpikir tingkat tinggi, yaitu:

\section{Tahap Preliminary}

\section{a. Persiapan analisis}

Tahap analisis ini merupakan langkah awal penelitian pengembangan. Peneliti menganalisis kurikulum dan sumber belajar dengan literatur yang ada.

\section{b. Desain}

Peneliti mendesaian soal-soal ujian sekolah matematika tipe HOTS dengan memperhatikan karakteristik konten, konstruk, dan kebahasaan yang disajikan pada table berikut ini.

Tabel 1. Karakteristik yang menjadi fokus prototype

\begin{tabular}{|c|c|}
\hline Konten & $\begin{array}{l}\text { Soal-soal tes mengukur } \\
\begin{aligned} & \text { HOTS sesuai dengan } \\
&- \text { Kurikulum } \\
&- \text { Kompetensi Dasar, } \\
&- \text { Indikator HOTS } \\
&- \text { Tujuan Pembelajaran }\end{aligned}\end{array}$ \\
\hline Konstruk & $\begin{array}{ll}\text { - } & \text { Mengembangkan } \\
& \text { kemampuan } \\
& \text { menganalisis, } \\
& \text { mengevaluasi serta } \\
& \text { mengkreasi } \\
\text { - } & \text { Memiliki banyak } \\
& \text { konsep } \\
\text { - } & \text { Sesuai untuk siswa } \\
& \text { kelas 6 SD } \\
\text { - } & \text { Mengandung } \\
\text { penalaran }\end{array}$ \\
\hline Bahasa & $\begin{array}{ll}\text { - } & \text { Sesuai dengan EYD } \\
\text { - } & \text { Soal Tidak } \\
& \text { membingungkan } \\
\text { - } & \text { Soal tidak } \\
& \text { mengandung } \\
& \text { penafsiran ganda }\end{array}$ \\
\hline
\end{tabular}

\begin{tabular}{|l|l|}
\hline & $-\quad$ Kejelasan Batasan \\
pertanyaan dan \\
jawaban \\
$-\quad \begin{array}{l}\text { Menggunakan Bahasa } \\
\text { yang umum }\end{array}$ \\
\hline
\end{tabular}

Setelah soal di desain dengan memperhatikan karakteristik di atas maka Langkah berikutnya adalah self evaluation.

\section{c. Self-evaluation}

Peneliti mengevaluasi hasil desain prototipe awal atau disebut Self evaluation guna mengetahui kekurangannya

\section{Prototyping}

a. Expert Review dan One-to-one Evaluation

Validasi ahli yaitu penilaian soal yang teah di desai sebelumnya yang dilakukan oleh ahli/pakar/ panelis untuk menelaah prototipe soal-soal ujian sekolah matematika tipe HOTS yang telah disiapkan oleh peneliti. Hasil evaluasi ini untuk mengetahui kelemahan pada prototipe awal dan merevisi atau memperbaiki soal yang dianggap belum layak untuk masuk dalam tahap berikutnya. Berikutnya dilakukan evaluasi one to one atau wawancara perorangan. Berberapa siswa satu persatu diminta memberikan masukan terkait soal yang elah dibuat. Hasil pada Langkah ini disebut prototype II.

\section{b. Small Group}

Soal-soal yang telah direvisi berikutnya dijui cobakan pada kelompok kecil dan dijadikan acuan dalam uji coba lapangan atau field test. Komentar-komentar siswa dicatat oleh peneliti untuk selanjutnya dijadikan dasar untuk merevisi desain prototype II. Hasil revisi tersebut dinamakan prototype III.

\section{c. Field Test}

Field test atau disebut dengan uji lapangan pada tahap ini adalah menguji cobakan soal-soal yang telah dibuat. Uji coba ini bertujuan untuk melihat potensi prototype sebelumnya terhadap hasil belajar. Berikut ini adalah contoh kartu soal ujian sekolah bagian uraian tipe HOTS beserta pembahasannya, yaitu soal nomor 10 dan soal nomor 11 . 


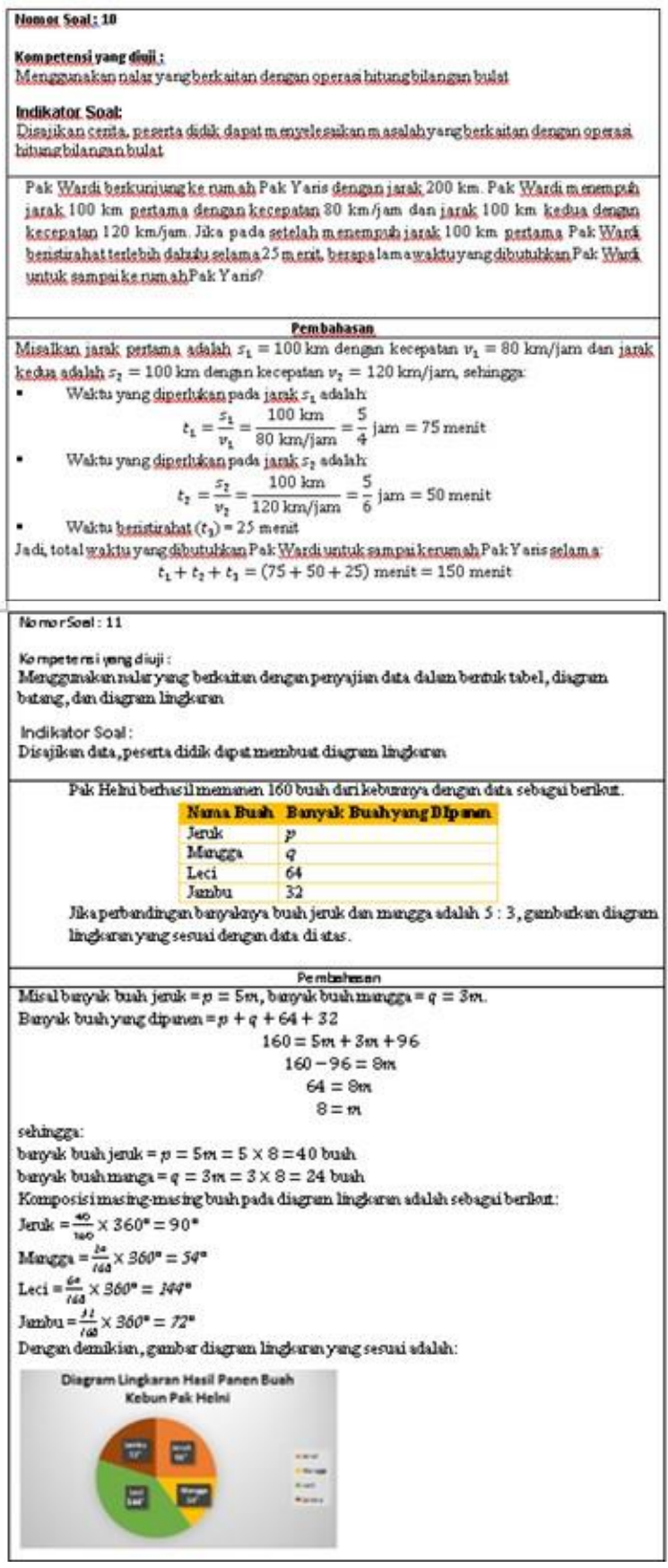

\section{Teknik Pengumpulan Data}

Teknik pengumpulan data yang digunakan adalah dengan tes tertulis. Tes terdiri dari 9 soal berbentuk pilihan ganda dan 2 soal berbentuk essai yang mengacu pada indikator kemampuan berpikir tingkat tinggi diantaranya:

(1).Menganalisis Informasi yang masuk harus dianalisis terlebih dahulu dan pisahkan berdasarkan factor penyebab yang kompleks hingga sederhana

(2).Mengevaluasi menilai solusi atau ide berdasarkan kriteria yang telah ditetapkan lalu dibuat dugaan sementara dan menguji hipotesis tersebut hingga membuat keputusan akhir berupa penerimaan atau penolakan

(3). Kreasi, yaitu menggeneralisasi ide lalu mendesain cara dalam mencari solusinya hingga ditemukannya suatu struktur baru.

\section{HASIL DAN PEMBAHASAN \\ Tahap Preliminary \\ 1. Persiapan analisis}

Pada tahap ini peneliti menganalisis SKL Ujian Sekolah Matematika yang telah disusun oleh dinas pendidikan dan kebudayaan kota bekasi yang berkerja sama oleh KKG Kota Bekasi (kisi-kisi terlampir). Soal terdiri dari 30 soal pilihan ganda dan 5 soal uraian dengan level kognitif L1, L2, dan L3. Kisi-kisi soal HOTS yang akan dikembangkan adalah yang memiliki level kognitif L3 (penalaran), dari 40 soal tersebut terdapat 9 soal pilihan ganda, yaitu soal nomor yaitu soal nomor 4, 8, 10, 12, 20, 21, 24, 27 dan 28, sedangkan pada soal essay memiliki 2 soal yang memiliki level kognitif L3 yaitu soal nomor 34, dan 35 .

\section{Desain}

Desain soal US tingkat SD TIPE HOTS yang dibuat, meliputi: Kisi-kisi soal HOTS, kartu soal HOTS dan Kunci jawaban alternatif/strategi jawaban dan Soal HOTS.

\section{Prototyping}

a. Validas ahli dan One-to-one Evaluation

Draf prototipe yang telah dievaluasi dan direvisi secara self evaluation perlu ditelaah lebih lanjut oleh para ahli atau pakar dan teman sejawat.

Pakar/ panelis yang memvalidasi soal-soal HOTS yang sudah dievaluasi mandiri adalah:

1. Widhiati Dwi Wijayanti, S. Pd., Guru Kelas 6 SDN Jati Asih

2. Nur Asmariani Siregar, M. Pd., Dosen Pendidikan Matematika Uinversitas Maritim Raja Ali Haji

3. Rizal Kamsurya, M. Pd., Dosen Pendidikan Matematika MNC Education College Jakarta

4. Widhi Adhi N.W., S. Pd., Guru Kelas 6 SDN Jati Kramat

Selain divalidasi oleh panelis, soal yang telah di desain juga di uji coba kepada satu orang siswa kelas 6 SD untuk melihat kualitas soal dari 
sudut pandang mereka dengan hasil sebagai berikut:

1. Pertanyaan butir soal No. 9 kurang jelas dan harus diperbaiki

2. Gambar grafik pada soal teralu kecil sehingga angka pada grafik sulit terbaca

3. Susunan pilhan jawaban pada soal pilihan ganda harus terurut dari yang terkecil hingga terbesar.

4. Penulisan angka pada soal atau jawaban yang mengandung niai mata uang harus mengikuti kaidah penulisan.

Setelah soal direvisi sesuai dengan saran dan masukan panelis serta uji coba one to one maka soal-soal tersebut merupakan prototype pertama yang siap dilakukan uji coba berikutnya.

\section{b. Small Group}

Hasil prototype pertama kemudian diuji cobakan pada kelompok kecil siswa kelas 6 SD yang berjumlah 5 siswa di luar subjek penelitian. Siswa tersebut diminta untuk mengamati soalsoal serta mengerjakannya sesuai dengan kemampuan yang dimiliki.

Untuk mensimulasi waktu, peneliti memberikan soal secara Hasil masukan-masukan dari siswa pada uji small group disajikan dalam table berikut.

\begin{tabular}{|c|c|}
\hline Saran & Keputusan Revisi \\
\hline $\begin{array}{lr}\text { Ukuran } & \text { font } \\
\text { pada } & \text { soal } \\
\text { diperbesar } & \text { agar } \\
\text { terbaca } & \text { dengan } \\
\text { baik. } & \end{array}$ & $\begin{array}{l}\text { Ukuran font } \\
\text { pada soal } \\
\text { diganti dari } 10 \\
\text { menjadi } 12 .\end{array}$ \\
\hline
\end{tabular}

Dari hasil uji coba small group yang merupakan prototype kedua didapat kesimpulan bahwa seluruh soal berkategori baik sehingga layak untuk digunakan.

\section{c. Field Test (Uji Lapangan)}

Komentar serta hasil uji coba prototipe II sebagai acuan untuk merevisi desain prototype II. Hasil revisi lalu diujicoba kembali pada subjek penelitian. Setelah itu soal ujian sekolah tipe HOTS prototype ketiga diuji cobakan pada subjek penelitian, yaitu siswa kelas 6 SDN Jati Asih yang berjumlah 25 siswa .

Berikut persentase hasil tes HOTS siswa yang telah dianalisis dan dihitung rata-rata nilai akhir.
Tabel 4.1. Distribusi Skor Rata-rata HOTS Siswa

\begin{tabular}{|l|l|l|l|}
\hline $\begin{array}{c}\text { Interval } \\
\text { Skor }\end{array}$ & Frekuensi & Persentase & Kategori \\
\hline $\mathbf{0 - 3}$ & 0 & 0 & Kurang \\
$\mathbf{4 - 7}$ & 3 & $12 \%$ & Cukup \\
$\mathbf{8 - 1 1}$ & 14 & $56 \%$ & Baik \\
$\mathbf{1 2}-\mathbf{1 5}$ & 8 & $32 \%$ & Sangat \\
& & & Baik \\
\hline
\end{tabular}

Dari table di atas terdapat 8 siswa (32\%) berkategori memiliki HOTS sangat baik, dan ada 14 siswa (56 \%) berkategori memiliki HOTS baik. Dapat disimpulkan ada 22 siswa ( $88 \%$ ) dari 25 berkategori sangat baik.

Berikut ini adalah contoh hasil jawaban siswa terhadap soal ujian sekolah tipe HOTS bagian uraian.

\section{Soal nomor 1}

Pak Wardi berkunjung ke rumah Pak Yaris dengan jarak $200 \mathrm{~km}$. Pak Wardi menempuh jarak $100 \mathrm{~km}$ pertama dengan kecepatan $80 \mathrm{~km} / \mathrm{jam}$ dan jarak $100 \mathrm{~km}$ kedua dengan kecepatan $120 \mathrm{~km} / \mathrm{jam}$. Jika pada setelah menempuh jarak $100 \mathrm{~km}$ pertama Pak Wardi beristirahat terlebih dahulu selama 25 menit, berapa lama waktu yang dibutuhkan Pak Wardi untuk sampai ke rumah Pak Yaris?

\section{Jawaban Siswa}

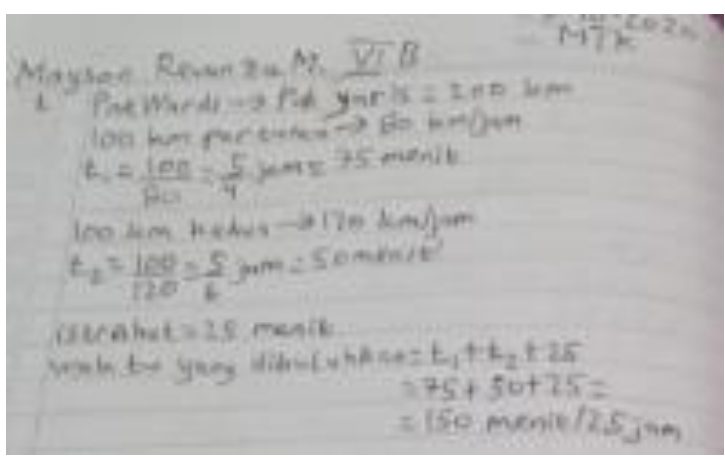

Dari jawaban di atas terlihat siswa telah mampu menganalisis soal dengan baik, terlihat dari penulisan poin-poin yang diketahui pada soal. Selain mampu menganalisis, siswa juga telah mampu mengerjakan soal dengan runtut, dimulai dari mencari waktu $\mathrm{t}_{1}$ dan $\mathrm{t}_{2}$ terlebih dahulu lalu menjumlahkan keduanya dengan waktu istirahat yang diketahui di soal.

\section{Soal nomor 2}

Pak Helni berhasil memanen 160 buah dari kebunnya dengan data sebagai berikut. 


\begin{tabular}{|l|l|}
\hline Nama Buah & Banyak Buah yang DIpanen \\
\hline Jeruk & $p$ \\
\hline Mangga & $q$ \\
\hline Leci & 64 \\
\hline Jambu & 32 \\
\hline
\end{tabular}

Jika perbandingan banyaknya buah jeruk dan mangga adalah $5: 3$, gambarkan diagram lingkaran yang sesuai dengan data di atas.

\section{Jawaban Siswa}

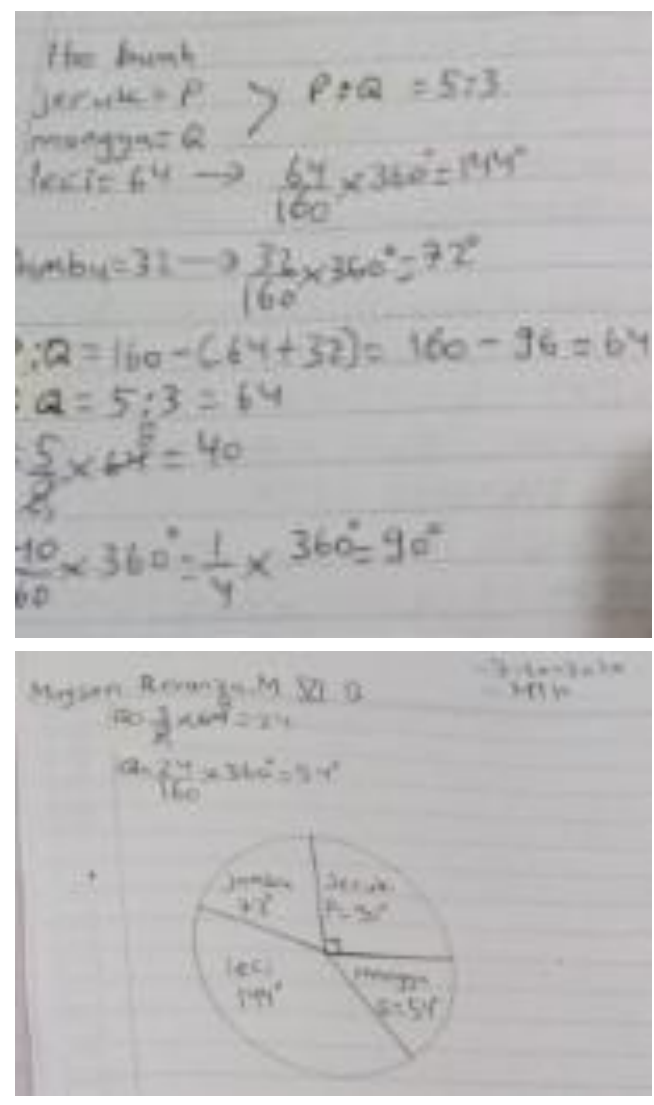

Pada soal uraian nomor 2 pun terlihat bahwa siswa telah mampu menganalisis dan mengidentifikasi, baik pada bagian soal maupun yang ditanyakan. Selain itu siswa sudah bisa mengkreasi dengan baik, yaitu dengan membuat diagram lingkaran secara proporsional.

\section{KESIMPULAN}

1. Penelitian ini telah menghasilkan suatu produk soal ujian sekolah bentuk pilihan ganda sebanyak 9 soal dan soal uraian sebanyak 2 soal yang valid dan sesuai dengan indicator HOTS.

2. 2. Soal ujian sekolah tipe HOTS yang dihasilkan memiliki efek potensi yang positif, terlihat dari hasil jawaban siswa yang menunjukkan bahwa siswa sudah mampu menganalisis, mengidentifikasi dan mengkreasi soal dengan baik serta $88 \%$ siswa mampu mendapatkan niai sangat baik.

\section{SARAN}

1. Bagi guru mata pelajaran matematika, agar dapat menggunakan soal tipe HOTS baik dalam pembelajaran di kelas maupun soalsoal ujian yang akan digunakan sebagai salah satu cara megejar ketertinggalan siswa di Indonesia dalam menjawa soal-soal HOTS jika dibandingkan dengan negara-negara lain yang mempunyai peringkat TIMSS lebih tinggi.

2. Bagi siswa, agar dapat lebih semnagat dan rajin lagi untuk mengasah kemampuan dalam mengerjakan soal-soal tipe HOTS sehingga kesulitan-kesulitan yang diteukan dalam mengerjakan soal tipe HOTS akan berkurang dan muncul suatu kebiasaan dalam mengerjakan soal-soal tipe HOTS.

\section{UCAPAN TERIMA KASIH}

Penulis menyampaikan terima kasih kepada Fakultas Matematika dan Ilmu Pengetahuan Alam Universitas Negeri Jakarta yang telah mendanai sepenuhnya penelitian ini serta semua pihak yang terlibat dalam penelitian ini

\section{DAFTAR PUSTAKA}

Akker, J.v.d. 1999. Principles and Methods of Development Research. Dalam J.v.d Akker (Ed). Design Approaches and Tools in Education and Training. Dordrecht: Kluwer Academic Publishers.

Badan Standar Nasional Pendidikan. 2011. Prosedur Operasional Standar Ujian Nasional.Jakarta: BSNP.

Butkowski, Jean. 1994. Improving Student Higher Order Thinking Skills in Mathematics. Tesis, Educational Resources Information Center

Depdiknas. 2003. Undang-Undang Republik Indonesia Nomor 20 Tahun 2003 tentang Sistem Pendidikan Nasional. Jakarta: Depdiknas 
2006. Peraturan Menteri Pendidikan

Nasional Nomor 23 Tahun 2006 tentang

Standar Kelulusan. Jakarta: Depdiknas. 2008. Panduan Analisis Butir Soal. Jakarta: Depdiknas.

-. 2008. Panduan Penulisan Soal

Pilihan Ganda. Jakarta: Depdiknas.

--. 2008. Panduan Penulisan Butir

Soal. Jakarta: Depdiknas.

2010. Peraturan Menteri Pendidikan

Nasional Nomor 45 Tahun 2010 tentang

Kriteria Kelulusan Peserta Didik.

Jakarta: Kemendiknas.

2010. Peraturan Menteri Pendidikan

Nasional Nomor 46 Tahun 2010 tentang

Pelaksanaan Ujian Sekolah/Madrasah

dan Ujian Nasional. Jakarta:

Kemendiknas.

Haeruman, L. D., Rahayu, W., \& Ambarwati, L. (2017). Pengaruh Model Discovery Learning Terhadap Peningkatan Kemampuan Berpikir Kritis Matematis dan Self Confidence Ditinjau Dari Kemampuan Awal Matematis Siswa SMA Di Bogor Timur. Jurnal Penelitian dan Pendidikan Matematika, 58-160.

Krathwohl, D. R. 2002. A revision of Bloom's Taxonomy: an overview - Theory Into Practice,College of Education, The Ohio State University Learning Domains or Bloom's Taxonomy: The Three Types of Learning, tersedia di www.nwlink.com/ donclark/hrd/bloom . html

Sugiyono. 2007. Statistika untuk Penelitian. Bandung : Alfabeta

Washington, D.Thompson,Tony. Mathematics Teachers' Interpretation of Higher Order Thinking In Bloom Taxonomy, International Electronic Journal of Mathematics Education Volume 3, Number 2, July 2008 tersedia di www.iejme.com 